\title{
Crime and Punishment in Classroom: a Game-Theoretic Approach for Student Cheating*
}

\author{
Marcelo de C. Griebeler ${ }^{\dagger}$
}

\author{
Contents: 1. Introduction; 2. The student cheating game; 3. Extensions; 4. Concluding remarks; \\ Appendix. Ommited proofs. \\ Keywords: Student Cheating, Game Theory, Academic Dishonesty. \\ JEL Code: C70, D01, I21.
}

We provide the microeconomic foundations of cheating in classroom through a static game with complete information. Our setting is composed by two students, who must choose whether or not to cheat, and a professor, who must choose how much effort to exert in trying to catch dishonest students. Our findings support the determinants of cheating found by the empirical literature, mainly those related to the penalty's level. It is also emphasized the importance of professors being well-motivated (with low disutility of effort) and worried about fairness in classroom. The several extensions of the baseline model reinforce the importance of the cost-benefit analysis to understand dishonest behavior in classroom. Finally, by relaxing the complete information assumption, we discuss the role of students' uncertainty about the professor's type and how low effort professors can send signals to create incentives for honest behavior.

Apresentamos os microfundamentos da "cola" em sala de aula através de um jogo estático de informação completa. Nossa estrutura é composta por dois alunos, os quais devem escolher se colam ou não, e um professor, o qual deve decidir o quanto de esforço empregará para tentar detectar alunos desonestos. Nossos resultados corroboram com os determinantes de cola encontrados pela literatura empírica, principalmente aqueles relacionados com a severidade da punição. Também é enfatizado a importância de professores serem bem motivados (com baixa desutilidade do esforço) e preocupados com justiça em sala de aula. As várias extensões do modelo base reforçam a importância da análise custo-benefício para entender comportamento desonesto em sala de aula. Por fim, ao relaxar a hipótese de informação completa,

\footnotetext{
${ }^{*}$ We thank the editor and an anonymous reviewer for their constructive comments. All the remaining errors are ours.

†Universidade Federal do Rio Grande do Sul, Faculdade de Ciências Econômicas (UFRGS/FCE), Departamento Economia e Relações Internacionais. Avenida João Pessoa, 52, Centro Histórico, Porto Alegre, RS, Brazil. CEP 90040-000. Tel +55 51 3308-3324. Email: marcelo.griebeler@ufrgs.br
} 
discutimos o papel da incerteza dos alunos sobre o tipo do professor, e como professores pouco esforçados podem enviar sinais para criar incentivos ao comportamento honesto.

\section{INTRODUCTION}

Academic dishonesty is a serious and widespread problem in the world. Although this practice may be found in institutions of all levels of education, it is better documented in colleges and universities. A recent survey conducted in the UK found that nearly 50,000 university students have been caught cheating from 2012 to 2015. The same data show non-EU scholars are the most likely to commit the offense, which suggests that student cheating is not restricted to a specific country (The Guardian, 2016). In fact, despite the absence of reliable data for regions such as Latin America, some studies have used alternative measures to estimate that violations of academic integrity have indeed risen in Latin American countries over the past two decades (García-Villegas, Franco-Pérez, \& Cortés-Arbeláez, 2015). A substantial rise in student cheating practices has been found in colleges and universities in the United States as well. McCabe, Trevino, \& Butterfield (2001), for instance, reports that the number of students that admit to engage in serious test cheating (e.g. copying from another student on the exam) increased from $39 \%$ in 1963 to $64 \%$ in 1993.

In this paper we propose a three-players static game with complete information in order to model the strategic relationship underlying the student's individual decision of cheating in classroom. Our setting is composed by two students and a professor, who must choose how much effort to exert in trying to catch dishonest students. In the baseline model, with two identical students, our findings highlight the role of the probability that the professor detects dishonesty in driving the student's decision. For instance, an equilibrium in which both students choose not to cheat requires that the probability of being caught committing the offense be large enough. This in turn requires a large level of professor's effort, which is mainly determined by his disutility of effort and the relative weight given to a fair classroom - without cheating-in his utility.

We also provide several extensions of the baseline model by relaxing some assumptions. First we analyze the basic static framework under incomplete information, when both students do not know the professor's type, whether lenient or severe. As a result of this modification, other equilibria may arise and the outcome depends mainly on how different the types are and the probability distribution adopted. Equilibria may also change when we relax the assumption that only the cheater student is punished and when we allow the "cheating technology" to be imperfect, such that the grade of student who copied is lower than that of the one who has the exam copied. In the former the possibility of an equilibrium in which both students cheat arises, while the latter increases the chance of a virtuous one. Yet, when we consider the case in which the utility of the student who has the exam copied is affected by the cheating behavior, and he has the option of avoiding that his classmate copies his exam, Nash equilibrium in pure strategies may no exist.

We also consider the case when there exists a further punishment for the dishonest student, that is, if the student is caught cheating, he is punished by losing a constant level of utility-due to failing grade in the course, suspension or expulsion, for example - in addition to zero grade in the exam. Under complete information, we find that a harder punishment decreases the minimum probability required to students choose not to cheat. This results resembles those of the classical analysis of Economics of Crime (Becker, 1968), in which the probability of being caught and the magnitude of the punishment drive the incentives of potential offenders. A more interesting extension is one that relaxes the assumption of complete information and allows the lenient professor to send a signal to students through a commitment that he will apply such a harder punishment in case of catching cheaters. In this scenario, 
when students believe that the probability of the professor being lenient is low, or there is a large difference between the two types of professor-reflected in their level of effort, for example-, or the cost of applying the harder punishment is not high enough, even the lenient professor can give incentives for both students to play fair.

A final extension allows students to be heterogeneous. They can be heterogeneous in terms of disutility of effort, for instance. This implies they choose different levels of effort and thus receive different grades. Different grades in turn implies different potential benefits for the cheater: the student with the lower grade has more to gain by cheating than the one with higher grade. This can be seen through the fact that the minimum probability that induces the student to play fair is decreasing in his own grade and increasing in the grade of the another student. Once again our model shows a feature of Economics of Crime, namely the higher the potential benefit of the offense, the more prone to commit it the individual is. In fact, the difference in terms of grades may be so large that playing not to cheat may be a dominant strategy for the student with higher grade regardless the probability of being caught cheating.

Although our framework presents similarities with the seminal model proposed by Gary Becker, there is an important distinction between them. ${ }^{1}$ In our cheating game each student is at the same time a potential offender and a potential victim. For instance, the set of potential outcomes includes one in which both students choose to cheat, case in which they both copy the exam of the other student and have his own copied by the other. On the contrary, in the classical version of Becker's model (Becker, 1968) there is no active role for victims. Given that his framework is not a game, the only agent to play is the potential criminal. Observe that if we considered that each student has his own crib note, made previously at home, and he used it to cheat, his choice about cheating or playing fair would depend exclusively on the probability of being caught. Thus the other student's choice no longer would affect his decision and no student would be a "victim". Unlike our baseline model, this version would be very similar to the one provided in Becker's seminal paper.

Furthermore, even police or law enforcer has no role in Becker's model. In our game, however, their role is played by the professor, which makes the probability of the cheater being caught endogenous. In fact, once we allow for the existence of two different types of professor, the value of the probability of catching cheaters depends on whether the "law enforcer in classroom" is lenient or severe. Even when the professor is severe, there is a possibility that his level of effort does not achieve the minimum required to create incentives for students to play fair. The actual professor type therefore affects directly the game's equilibrium. This feature is even more salient when we consider the extended model with incomplete information and possibility of signaling. In this case, the active role of the professor can also affect the level of uncertainty that students face-when the lenient chooses to signal in order to mimic the severe's behavior, for example. The existence of different types of "law enforcers", and the consequent uncertainty about which the true one is, is a novel contribution of our paper when compared to the standard literature on economics of crime, and to Becker's paper in particular.

Our contribution to the literature is to provide a theoretical framework that is able to capture all the strategic features of students' choice of cheating, and professor's choice of how much effort to exert in order to catch cheaters. To the best of our knowledge, the vast majority of literature on academic dishonesty adopt a psychological approach to investigate the determinants of student cheating (Macfarlane, Zhang, \& Pun, 2014; McCabe et al., 2001). On the one hand, individual factors such as gen-

${ }^{1}$ Bunn, Caudill, \& Gropper (1992) is the first study to present similarities and differences between cheating and the crime of theft following Becker's approach. The two main differences found by its authors are: a professor has a greater variety of devices to affect the costs of cheating than a police officer (e.g. disperse the class during examinations, reducing density and increasing the costs of cheating); and exam answers have a public good dimension, such that unlike "the watch stolen from its owner, answers on exams are not taken from the owner, but only copied" (Bunn et al., 1992, p.199). This second characteristic creates the free-riding problem in classroom. 
der, grade point average (GPA), work ethic, competitive achievement striving and self-esteem have been found as having significant influence on the prevalence of cheating (Baird, 1980; Ward \& Beck, 1990). On the other hand, contextual factors such as faculty response to cheating, sanction threats, social learning, and honor codes have also been shown to influence dishonest behavior (Michaels \& Miethe, 1989). In fact, even those studies which perform economic cost benefit analysis often do it empirically, without a microeconomic model to support their results (Bisping, Patron, \& Roskelley, 2008; Bunn et al., 1992).

An important exception is the study of Briggs, Workman, \& York (2013), which uses game theory to analyze collaboration in academic cheating. The authors provide a relevant discussion about the use of mathematical utility modeling - and thus game theory-with respect to ethics. Based on the reasoning developed in works such as Gibson (2003), they argued that incorporation of games such as the Prisoner's Dilemma into the ethics issues - and thus in cheating as well-may be useful to better understand costs and benefits involved. However, their model focuses in collaboration in take-home tasks rather than in-class activities, and thus is substantially different from the framework we develop in this paper.

In particular, Briggs et al. (2013) studies collusion among students by presenting a game of team cheating, in which each student from a group of three people must choose whether or not to cheat, and must also choose whether or not to tattle on the cheater member to the professor. The probability of succeeding in cheating is endogenous, given that whenever at least one student tattles, the cheater is caught and punished. Observe that the model presented by those authors focuses on collaborative cheating rather than individual cheating, which makes it quite different from ours. Moreover, there is no active role for the professor, since the punishment is exogenously defined and the probability of cheaters being caught is determined by students's behavior.

The game-theoretic approach we employ allows us to provide both positive and normative conclusions. ${ }^{2}$ First, our model fits several stylized facts found by empirical studies, such as the effect of higher penalties in decreasing prevalence of cheating, the inverse relationship between GPA and cheating behavior, and the importance of peer cheating behavior in explaining it (McCabe et al., 2001). Second, it also provides insights that can help reduce cheating on campuses. Some of them had already been found effective by the literature, such as harsh penalties imposed by both the institution and the professor. Others, however, have not received much attention, including hiring high effort professors, who value fairness in classroom. As we show below, a necessary condition for the existence of a virtuous equilibrium (without cheating) is that the professor do not be lenient.

The rest of the paper is organized as follows. In the following section we present our baseline model, composed by two identical students and a professor. We discuss the incentives each one faces and describe their processes of choice. This section also establishes necessary and sufficient conditions for the existence of a Nash equilibrium without cheating. Section 3 extends the model in several directions. Section 4 concludes and suggests some other extensions. The proofs of propositions omitted in the text are shown in the Appendix.

\section{THE STUDENT CHEATING GAME}

\subsection{The baseline model}

Our baseline model is composed by two identical students, $A$ and $B$, and one professor (or teacher). There will be an exam in the course that the professor is in charge. Each student must choose his level of effort in studying and the professor must choose his effort to detect and punish in-class cheating. Whenever a student chooses to cheat, he does not study, such that his level of effort is equal to zero. All

\footnotetext{
${ }^{2}$ Although it is plausible to consider the absence of cheating as a social objective, we have not proved formally that this is the case yet. However, section 2.1.3 shows that the equilibrium that involves no cheating is Pareto-dominant when the professor exerts a positive level of effort, which we can consider the most common case.
} 
these actions are chosen before the exam happens, there is no communication among the players and the information is complete, such that we can model this strategic situation as a three-players static game.

We consider only one type of academic dishonesty, namely the action of one student of copying from the another student's exam without his consent or knowledge. Therefore, we rule out common cheating practices such as helping someone on the exam and using a crib note. We also do not consider academic cheating in take-home tasks, such as representing someone else's work as your own (e.g. sharing another's work, purchasing a term paper or test questions in advance, paying another to do the work for you). Given this assumption, whenever the professor detects a dishonesty action, he can punish only the student that copied the exam. We assume the punishment sets the dishonest student's grade equal to zero. If the student succeeds in cheating, his grade is equal to that of the other student.

The student's utility is a $C^{2}$ function and is given by $U_{i}\left(N_{i}, e_{i}\right)$, where $N_{i}$ is his grade on the exam and $e_{i} \in[0,+\infty)$ is his level of effort in studying, with $i=A, B$. We assume the marginal utility of the grade is positive, $\partial U_{i} / \partial N_{i}>0$, and the marginal utility of the effort is negative, $\partial U_{i} / \partial e_{i}<0$. Given the possibility of cheating, the grade of student $i$ depends on his effort, the other student's grade, the probability of being caught cheating $p \in[0,1]$, and mainly on his chosen strategy, whether cheating (C) or "playing fair" (PF). Moreover, given that players are identical, they have the same utility as well as the same grade function. There are four possible cases to consider:

(i) Both students $A$ and $B$ choose to cheat: as in this case none of them exerts any effort in studying, both their grades are equal to zero, $N_{A}=N_{B}=0$.

(ii) Both students $A$ and $B$ choose to "play fair": in this case each player exerts his optimal level of effort $e_{i}^{*}>0$, such that the grades are $N_{A}\left(e_{A}^{*}\right)$ and $N_{B}\left(e_{B}^{*}\right)$. Given the assumption of identical players, $N_{A}\left(e_{A}^{*}\right)=N_{B}\left(e_{B}^{*}\right)$.

(iii) student $A$ plays fair while student $B$ cheats: the grade of the student $A$ is $N_{A}\left(e_{A}^{*}\right)$ while the expected grade of the student $B$ is $N_{B}=N_{A}\left(e_{A}^{*}\right)(1-p)$.

(iv) student $B$ plays fair while student $A$ cheats: here we have the opposite of the case (iii), such that $N_{A}=N_{B}\left(e_{B}^{*}\right)(1-p)$ and $N_{B}\left(e_{B}^{*}\right)$.

Student's grade is increasing in his effort in studying. However, the return of the effort is decreasing. We also assume some other conditions on the behavior of this function, which may be seen equal to the Inada conditions. The assumption below summarizes and formalizes the features of the grade function.

Assumption 1. The student's grade is a $C^{2}$ function of his own effort $e_{i}$, given by $N_{i}:[0, \infty) \rightarrow[0,10]$, and satisfies the following properties: $N_{i}^{\prime}\left(e_{i}\right)>0, N_{i}^{\prime \prime}\left(e_{i}\right)<0, N_{i}(0)=0, \lim _{e_{i} \rightarrow+\infty} N_{i}^{\prime}\left(e_{i}\right)=0$, and $\lim _{e_{i} \rightarrow 0} N^{\prime}\left(e_{i}\right)=+\infty$.

Whenever student $i$ chooses to play fair, he must maximize his utility by choosing the optimal level of effort $e_{i}^{*}$. The first order condition of his problem is then given by

$$
\frac{d U_{i}}{d e_{i}}=\frac{\partial U_{i}}{\partial N_{i}} N_{i}^{\prime}+\frac{\partial U_{i}}{\partial e_{i}}=0,
$$

which can be understood as the equality of the marginal benefit of effort, through the increase in the student's grade, and its marginal disutility. We discuss the existence of such an optimal choice below. 
Proposition 2. Suppose that the student's utility function has the following further characteristics:

$$
\begin{gathered}
\frac{d U_{i}(0,0)}{d e_{i}}>0 ; \\
\frac{\partial^{2} U_{i}}{\partial e_{i}^{2}}<0, \quad \frac{\partial^{2} U_{i}}{\partial N_{i} \partial e_{i}} \leq 0, \quad \text { and } \quad \frac{\partial^{2} U_{i}}{\partial N_{i}^{2}}<0 ; \\
\lim _{e_{i} \rightarrow+\infty} \frac{\partial U_{i}}{\partial N_{i}}<+\infty \quad \text { and } \quad \lim _{e_{i} \rightarrow+\infty} \frac{\partial U_{i}}{\partial e_{i}}=-\infty .
\end{gathered}
$$

Then the first order condition of the student's problem (1) has an unique global maximizer at some interior point $e_{i}^{*}$.

The first assumption of the above result means that the total marginal effect of the effort is positive when $e_{i}=0$. This is equivalent to make the assumption that $-\partial U_{i}(0) / \partial e_{i}<\partial U_{i}(0) / \partial N_{i} \cdot N_{i}^{\prime}(0)$, that is, the marginal gain of utility due to the increase in the grade is higher than the disutility of effort when the level of effort is zero. Thus, our model rules out "very lazy" students. The proposition also assumes that both the disutility of effort and the marginal utility of the student's grade increase at increasing rates for all levels of effort and grades, $\partial^{2} U_{i} / \partial e_{i}^{2}<0$ and $\partial^{2} U_{i} / \partial N_{i}^{2}<0$, respectively.

Although the assumptions made about the second derivatives are quite standard when one want to guarantee concavity, it is possible to think about at least two cases in which they could be relaxed. The first one is when there exists a minimum grade for passing the exam, say $N \in(0,10)$. In this case, it is reasonable to assume that $\partial U_{i} / \partial N_{i}$ is not monotonically decreasing, instead there must exist a neighborhood of $N$ where the marginal utility of the grade is increasing. This means that $\partial^{2} U_{i} / \partial N_{i}^{2}>0$ in such neighborhood, which may make the student's optimal choice be different from the one of our baseline model.

The second case happens when the student is of the type which always wants to achieve the maximum grade. This may fits students who want to graduate with honors, for example. Students with such behavior present increasing marginal utility of the grade, such that $\partial^{2} U_{i} / \partial N_{i}^{2}>0$ for all $N_{i} \in(0,10)$. The same comment about the previous case, concerning the potential changes in the optimal choice, applies to here. However, it is possible to guarantee the concavity of $U$ if the magnitude of the second derivative is relatively small (see equation (A-2) in the proof of proposition 2). In fact, this alternative may also ensure a well-behaved solution in the case with a minimum grade.

The assumption that the mixed partial derivative is non-positive means that the marginal utility of the grade is higher when the level of effort is low than when it is high, ceteris paribus. The ideia behind this assumption is that the student gets a higher marginal pleasure when the grade can be achieved with less effort. The alternative assumption, namely positive mixed partial second derivative, suggests a behavior in which the student feels that his effort is rewarding, such that the marginal utility increases with the level of effort. Once again, it is possible to obtain the concavity of $U$ with such alternative assumption as long as we impose bounds in the magnitude of the derivative.

Some comparative statics results may help us to understand the student's behavior.

Proposition 3. The student's optimal level of effort is a function that:

(i) is decreasing in the marginal disutility of effort;

(ii) is increasing in the marginal utility of his own grade; and

(iii) is increasing in the return of the effort on higher grades.

The professor's utility depends on the grades of each student, the probability of catching students cheating in class, and his effort to catch in-class cheating $\theta \in[0,+\infty)$. We model it as a $C^{2}$ function given by $W\left(N_{A}, N_{B}, p, \theta\right)$. We assume the professor gets more satisfaction as students' grades increase, 
that is, $\partial W / \partial N_{A}=\partial W / \partial N_{B}>0$. There is also an disutility of effort, such that $\partial W / \partial \theta<0$. Finally, the professor wishes the fairest possible class, which means the marginal utility of the probability of catching any student cheating is positive, $\partial W / \partial p>0$. We must impose some further regularities in the professor behavior.

Assumption 4. The professor's utility function has the following further characteristics: (i) it is strictly concave for all levels of effort, that is, $d^{2} W / d \theta^{2}<0$ for $\theta \in[0, \infty)$; and (ii) $\lim _{\theta \rightarrow+\infty} d W / d \theta=-\infty$.

The characteristics of the probability function are quite standard and satisfy the Inada conditions, as we highlight below.

Assumption 5. The probability of catching any student cheating is a $C^{2}$ function of the professor's effort $\theta$, given by $p:[0, \infty) \rightarrow[0,1]$, and satisfies the following properties: $p^{\prime}(\theta)>0, p^{\prime \prime}(\theta)<0, p(0)=0$, $\lim _{\theta \rightarrow+\infty} p^{\prime}(\theta)=0$ and $\lim _{\theta \rightarrow 0} p^{\prime}(\theta)=+\infty$.

We consider two types of professor, depending on the relative magnitude of his disutility of effort. The lenient professor is characterized by a very high disutility — or a very low marginal utility from the increase in the fairness of the class-when his level of effort is zero, such that $d W^{L}(a, b, 0,0) / d \theta \leq 0$ for all constant $a, b \in[0,10]$. This means that any effort to catch dishonest behaviors does not leave the lenient professor better off, regardless students' grades. In other words, for this type of professor the benefit from the increase in the probability of catching is not higher than the desutility of effort. ${ }^{3}$ Observe that increases in professor's effort—and thus in probability of catching-do not positively impact the grades for any students' choices, so we can disregard such an effect in this case.

The other type is the severe professor, who is characterized by $d W^{S}(a, b, 0,0) / d \theta>0$ for all constant $a, b \in[0,10]$. Now an initial effort is worth, because the marginal benefit of increasing the probability $p$ is higher than the disutility caused by such an effort. However, this case presents a further complexity, such that we may have to consider the effect that the higher probability has on the students' grades. For example, if only one of the students cheats, say student $A$, we have $a=N_{B}\left(e_{B}^{*}\right)(1-p)$ and $b=N_{B}\left(e_{B}^{*}\right)$, and increases in $p$ make $a$ decrease. The impact on the severe professor's utility is then $-\partial W^{S} / \partial N_{A}$. $N_{B} p^{\prime}<0$. We must later analyze whether such an effect is large enough to overcome the other two, which would make the severe professor mimic the lenient's choice.

As usual, the severe professor chooses his optimal level of effort $\theta^{*}$ by maximizing his utility. The first order condition of his problem when student $A$ cheats and student $B$ plays fair is given by

$$
\frac{d W^{S}}{d \theta}=p^{\prime}\left(\frac{\partial W^{S}}{\partial p}-\frac{\partial W^{S}}{\partial N_{A}} N_{B}\right)+\frac{\partial W^{S}}{\partial \theta}=0 .
$$

While marginal benefit of the professor's effort is only $\partial W^{S} / \partial p \cdot p^{\prime}>0$, the marginal cost is composed by the direct disutility of effort, $\partial W^{S} / \partial \theta<0$, and the potential impact on the student $A$ 's grade, $-\partial W^{S} / \partial N_{A} p^{\prime} N_{B}<0$. When student $A$ plays fair and student $B$ cheats, the professor's FOC is similar to (2), except by the exchange of subscripts. For the other two cases (both students cheat and both students play fair), the FOC is also similar to (2), but now without the effect on the grades.

Proposition 6. Suppose that the severe professor's utility function satisfies Assumption 4. Then the first order condition of his problem (2) has an unique global maximizer at some interior point $\theta^{*}>0$.

\footnotetext{
${ }^{3}$ Literature has found evidence that the prevalence of this type of professor is not negligible. McCabe et al. (2001), for example, reports that transgressions in classroom are often overlooked or treated lightly by professors who do not want to become involved in bureaucratic procedures designed to adjudicate allegation of academic dishonesty. On the student-professor relationship and its effects on cheating in classroom see also Stearns (2001).
} 
The assumptions assumed in order to assure the existence of the global maximizer above are quite standard, as we have already discussed. We can now establish comparative statics results for the professor's optimal choice.

Proposition 7. The severe professor's optimal level of effort is a function that:

(i) is decreasing in the marginal disutility of effort;

(ii) is decreasing in the marginal utility of students' grade;

(iii) is increasing in marginal utility of the probability of catching students cheating; and

(iv) is increasing in the marginal return of effort on the probability.

The above result states that when marginal benefits or marginal costs change, the optimal choice changes as well. While items (i) and (ii) are related to marginal costs, items (iii) and (iv) are associated to marginal benefits. This explains why in the former the relationship is inverse and in the latter it is direct. Item (ii) deserves some attention. Observe that the students' grades affect the professor's level of effort only if one of them chooses to cheat. In this case, there is a negative effect: higher effort implies higher probability, which in turn decreases the cheater's grade. Therefore, the optimal level of effort decreases when there are increases in $\partial W / \partial N_{i}$, with $i=12$, because now the negative impact of increases in the probability of catching on the grades is higher.

We can sum up the game in the two payoff matrices below. For the sake of simplicity we henceforth set $U(0,0)=0$ and $W(0,0,0,0)=0$.

(a) Professor chooses $\theta^{*}=0$

\section{Student B}

\begin{tabular}{|c|c|c|}
\hline \multirow[b]{4}{*}{ Student A } & cheat & fair play \\
\hline & $U_{A}(0,0)$ & $U_{A}\left(N_{B}\left(e_{B}^{*}\right), 0\right)$ \\
\hline & $U_{B}(0,0)$ & $U_{B}\left(N_{B}\left(e_{B}^{*}\right), e_{B}^{*}\right)$ \\
\hline & $W(0,0,0,0)$ & $W\left(N_{B}\left(e_{B}^{*}\right), N_{B}\left(e_{B}^{*}\right), 0,0\right)$ \\
\hline \multirow{3}{*}{ fair play } & $U_{A}\left(N_{A}\left(e_{A}^{*}\right), e_{A}^{*}\right)$ & $U_{A}\left(N_{A}\left(e_{A}^{*}\right), e_{A}^{*}\right)$ \\
\hline & $U_{B}\left(N_{A}\left(e_{A}^{*}\right), 0\right)$ & $U_{B}\left(N_{B}\left(e_{B}^{*}\right), e_{B}^{*}\right)$ \\
\hline & $W\left(N_{A}\left(e_{A}^{*}\right), N_{A}\left(e_{A}^{*}\right), 0,0\right)$ & $W\left(N_{A}\left(e_{A}^{*}\right), N_{B}\left(e_{B}^{*}\right), 0,0\right)$ \\
\hline
\end{tabular}

(b) Professor chooses $\theta^{*}>0$

\section{Student B}

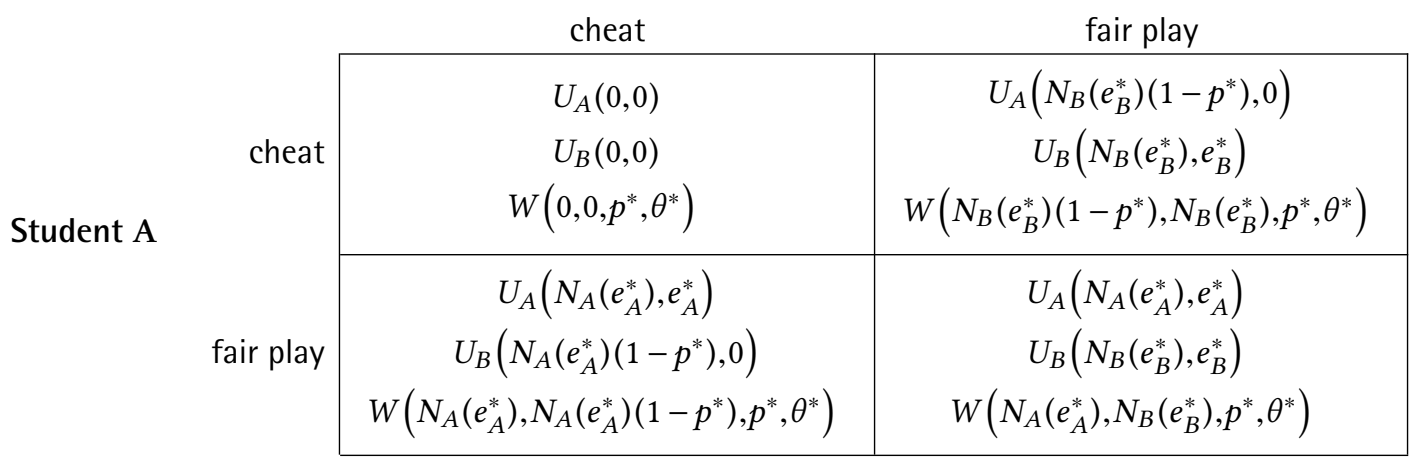




\subsubsection{The student's decision}

Let us consider the decision of student $A$. As we are assuming symmetry, the same results are valid for student $B$. First, suppose that the professor chooses $\theta^{*}=0$ and student $B$ chooses to cheat. In this case, student $A$ chooses to play fair, because

$$
U_{A}\left(N_{A}\left(e_{A}^{*}\right), e_{A}^{*}\right)>0=U_{A}(0,0) .
$$

If the professor chooses $\theta^{*}=0$ and student $B$ chooses to play fair, student $A$ now is better off by choosing to cheat, because

$$
U_{A}\left(N_{A}\left(e_{A}^{*}\right), e_{A}^{*}\right)<U_{A}\left(N_{B}\left(e_{B}^{*}\right), 0\right)=U_{A}\left(N_{A}\left(e_{A}^{*}\right), 0\right),
$$

where we once again use the symmetry assumption.

Suppose now that the professor chooses $\theta^{*}>0$. If student $B$ chooses to cheat, student $A$ chooses to play fair, because his payoffs are the same as those given by (3). However, if student $B$ chooses to play fair, the choice of student $A$ depend on the probability of being caught cheating. In fact, student $A$ plays fair if and only if

$$
U_{A}\left(N_{A}\left(e_{A}^{*}\right), e_{A}^{*}\right) \geq U_{A}\left(N_{B}\left(e_{B}^{*}\right)\left(1-p^{*}\right), 0\right) .
$$

The next proposition helps us understand the student's behavior. ${ }^{4}$

Proposition 8. There exists a probability of being caught cheating $p^{\min } \in(0,1)$ such that

$$
U_{i}\left(N_{i}\left(e_{i}^{*}\right), e_{i}^{*}\right)=U_{i}\left(N_{j}\left(e_{j}^{*}\right)\left(1-p^{\min }\right), 0\right),
$$

for $i, j=A, B$ and $i \neq j$.

As the proof of the proposition shows—see Appendix, section A.1—, function

$$
U_{A}\left(N_{A}\left(e_{A}^{*}\right), e_{A}^{*}\right)-U_{A}\left(N_{B}\left(e_{B}^{*}\right)\left(1-p^{*}\right), 0\right)
$$

is increasing in $p$ : the higher the probability of being caught, the stronger the incentive to play fair. Thus, the above result implies playing fair is a strictly dominant strategy for student $A$ if and only if $p^{*}>p^{\min }$. Recall that we are assuming identical students, such that the same reasoning can be used to show that student $B$ chooses to play fair regardless the another student's choice if and only if $p^{*}>p^{\min }$. Yet, when $p^{*}=p^{\min }$ both students are indifferent between playing fair and cheating.

We can sum up the students' best choices with the support of the above two payoff matrices. In order to do so, let us disregard the professor's decision for a while. In the first matrix, given $\theta=0$, there are two equilibria: student $A$ plays fair and student $B$ cheats and; student $A$ cheats and student $B$ plays fair. In the second one, given $\theta^{*}>0$, there are three cases to consider. First, if $p^{*}<p^{\min }$, then we have the same two equilibria found in matrix $\theta=0$. Second, if $p^{*}>p^{\min }$, both students choose to play fair. Third, if $p^{*}=p^{\min }$, then there are three equilibria: both choose to play fair; student $A$ plays fair and student $B$ cheats and; student $A$ cheats and student $B$ plays fair. We must now study the professor's best choice.

\footnotetext{
${ }^{4}$ An important remark must be made here. Propositions 8, 9, 11, 1, 12 e 13 assume that $p$ is an exogenous variable. As the presence of the professor as a player shows, this is not the case when we analyze the whole game. In fact, $p^{\text {min }}$ as defined in the proposition 8 may not be reached by some types of professors. However, this artifice allows us to define a fundamental threshold for our results and does not create any drawback in terms of theory.
} 


\subsubsection{The professor's decision}

Let us start with the lenient one. One can readily see that this type has a dominant strategy, namely $\theta^{*}=0$. The assumption that his disutility of effort is relatively high implies $W^{L}(a, b, 0,0)>W^{L}\left(a, b, p^{*}, \theta^{*}\right)$ for any $a, b \in[0,1]$. As $\partial W / \partial N_{i}>0$, it also implies $W^{L}(a, a, 0,0)>W^{L}\left(a, a\left(1-p^{*}\right), p^{*}, \theta^{*}\right)$. This covers all possibilities.

Despite the larger complexity of the behavior of the severe professor, there are two straightforward cases. First, suppose that both students choose to cheat. In this case we have $W^{S}(0,0,0,0)=$ $0<W^{S}\left(0,0, p^{*}, \theta^{*}\right)$, such that his best choice is $\theta^{*}>0$. When both students choose to play fair, his best choice is once more $\theta=\theta^{*}>0$, because $W^{S}\left(N_{A}\left(e_{A}^{*}\right), N_{B}\left(e_{B}^{*}\right), 0,0\right)<W^{S}\left(N_{A}\left(e_{A}^{*}\right), N_{B}\left(e_{B}^{*}\right), p^{*}, \theta^{*}\right)$, which is implied by the assumption that defines the severe type.

Suppose now that student $A$ cheats and student $B$ plays fair. The severe professor's best choice is $\theta^{*}>0$ if and only if

$$
W^{S}\left(N_{B}\left(e_{B}^{*}\right)\left(1-p^{*}\right), N_{B}\left(e_{B}^{*}\right), p^{*}, \theta^{*}\right) \geq W^{S}\left(N_{B}\left(e_{B}^{*}\right), N_{B}\left(e_{B}^{*}\right), 0,0\right) .
$$

Recall that the definition of severe professor states that $p^{\prime} \cdot \partial W^{S} / \partial p+\partial W^{S} / \partial \theta>0$ when $\theta=0$, which means that he makes a positive effort whenever it has no effect on the students' grades. Thus, we must check whether the marginal effect of the effort on the grades, namely their decrease as a result of the increase in the probability of catching dishonest students, is enough to overcome the benefit measured by the above derivative. Formally, the severe professor's best choice is $\theta^{*}$ if and only if

$$
\left.\left(p^{\prime} \frac{\partial W^{S}}{\partial p}+\frac{\partial W^{S}}{\partial \theta}\right)\right|_{\theta=0} \geq\left.\frac{\partial W^{S}}{\partial N_{A}} N_{B} p^{\prime}\right|_{\theta=0} .
$$

Notice that when the above inequality is strict $\theta^{*}>0$ strictly dominates $\theta^{*}=0$, and when the equality holds the professor is indifferent between the two strategies. Furthermore, one can readily see that when student $A$ plays fair and student $B$ cheats, the severe professor's best choice is $\theta^{*}>0$ if and only if $\left.\left(p^{\prime} \cdot \partial W^{S} / \partial p+\partial W^{S} / \partial \theta\right)\right|_{\theta=0}>\left.\left(\partial W^{S} \partial N_{B} N_{A} \cdot p^{\prime}\right)\right|_{\theta=0}$.

Before analyzing game's equilibria, an important remark must be made. A quite strong assumption that we made is that the effect of the students' grades on the professor's utility is independent from the way the grade is obtained, whether fairly or through cheating. Although this drawback is partially addressed by the presence of the probability $p$ in the professor's utility, which means that there is a direct effect of fairness on his welfare, we must discuss how our results would change when such assumption is relaxed. Observe that our original assumption allows the existence of a kind of "pact of mediocrity", in which professor may choose not to exert any effort to try to catch dishonest students, and thus to increase their grades. In fact, this is the case of the lenient professor and, as we commented in footnote 3 , this situation is not rare.

Let now the professor utility function be given by $W\left(N_{A}, N_{B}, \theta, p\right)-\psi$, where $\psi>0$ whenever at least one student cheats and $\psi=0$ whenever both play fair. Here we are assuming that, once the professor finds out that there is cheating in classroom, he is not able to identify who the offender is. Thus, his disutility depends only on the presence of cheating, and not on the number of cheaters. As it is possible to note below, if we relaxed such assumption, there would be no change in our analysis.

For the severe professor, when student $A$ plays fair and student $B$ cheats, the best choice is $\theta^{*}>0$ if and only if

$$
W\left(N_{A}\left(e_{A}^{*}\right), N_{B}\left(e_{B}^{*}\right), 0,0\right)-\psi \leq W\left(N_{A}\left(e_{A}^{*}\right), N_{B}\left(e_{B}^{*}\right)\left(1-p^{*}\right), p^{*}, \theta^{*}\right)-\psi .
$$

The above expression shows that there is no change in the professor's choice. In fact, once both matrices (those associated to $\theta^{*}=0$ and to $\theta^{*}>0$ ) are affected equally, there is no change in the comparisons made 
by the professor and so the equilibria remain the same. This conclusion also holds when the professor's utility is affected in different ways (by a decrease in the impact of cheater's grade, for instance), since any disutility would have the same effect in both matrices. Thus, we can invoke the ordinal property of the utility function and keep our original simplifying assumption.

\subsubsection{Discussion on Nash Equilibria}

We have already found all the players' best choices. Now we are able to compute all the several possible Nash equilibria of the baseline game. However, most of those outcomes involve at least one student cheating. In this section we are particularly interested in finding conditions to guarantee existence and uniqueness of what we call the virtuous equilibrium, a Nash equilibrium in which both students play fair. Our interest in this equilibrium can be explained by the fact that it is Pareto-dominant when $\theta^{*}>0$ : once this outcome is reached, the professor would have a loss in his utility if we tried to increase welfare of some student. Although this is not the case when $\theta^{*}=0$, we can justify its importance by arguing that $\theta^{*}>0$ is the most common case in practice. In order to do so, we first establish an important condition:

$$
\left.\left(p^{\prime} \frac{\partial W^{S}}{\partial p}+\frac{\partial W^{S}}{\partial \theta}\right)\right|_{\theta=0} \geq \max \left\{\left.\frac{\partial W^{S}}{\partial N_{A}} N_{B} p^{\prime}\right|_{\theta=0},\left.\frac{\partial W^{S}}{\partial N_{B}} N_{A} p^{\prime}\right|_{\theta=0}\right\},
$$

which can be seen equal to (8) when the students are symmetrical-in this case $\partial W^{S} \partial N_{B} N_{A} \cdot p^{\prime}=$ $\partial W^{S} \partial N_{A} N_{B} \cdot p^{\prime}$.

Our main result in this section is given by the next proposition. ${ }^{5}$

Proposition 9. The baseline game played by student $A$, student $B$, and the professor has the virtuous equilibrium if and only if $p^{*} \geq p^{\min }$, the professor is severe and condition (10) holds. Furthermore, if the above inequality is strict and condition (10) holds with strict inequality, then the equilibrium is unique.

The idea underlying the above result is that the virtuous equilibrium can only happen if professor gives students incentives to behave honestly. This is done by increasing the probability of detecting cheating above the threshold $p^{\text {min }}$, which in turn requires that the professor make a positive effort, which is impossible when he is lenient. Thus, the equilibrium with no cheating is only possible when the professor is severe and his marginal disutility from decreasing grades is relatively low, as established by condition (10). The virtuous outcome is the only Nash equilibrium of the game whenever none of the players is indifferent between their strategies, which is guaranteed when $p^{*}>p^{\min }$ and condition (10) is satisfied with strict inequality.

Although the virtuous equilibrium is the most relevant, it is important to study the other equilibria involving cheating. Let us start with the case in which the professor chooses $\theta^{*}=0$, that is, he is lenient or severe and condition (10) does not hold. As can be seen in the matrix presented above, the equilibria in this scenario are (play fair,cheat, 0 ) and (cheat,play fair,0). Once the professor provides no incentive to study through punishment, the possiblity of virtuous equilibrium is ruled out. However, given that assumption that excludes "very lazy students", studying is always preferred over having grade equal to zero. As students are homogenous, there is a coordination problem about defining who will be the cheater and who will be the studying one.

If the game were repeated, some alternatives to solve the coordination problem would be to allow mixed strategies and to consider the learning effects on the students' behaviors. Yet, in a static game like ours we must consider other options, such as pre-exam communication and focal point. Suppose that one day before the exam begins, students can talk and reach a self-enforcing agreement about who

\footnotetext{
${ }^{5}$ Proofs of propositions 9 and 13 are in the text, thus they are not shown in the Appendix like the demonstrations of the other results.
} 
will cheat and who will study. This would solve the problem, but observe that the characteristic that would determines the students' roles must be one that is not taken into account in students' utility, and it is not a straightforward task, as an example below shows.

Something similar happens when one think about possibilities of focal points: some characteristic that is not reflected in their welfare must be the criterion to choose between the two students. In a one shot game in which players are homogeneous, it is not easy to find such a characteristic. One can think that one student, say $A$, gives more value to ethics than his classmate and both know that, such that the focal point would indicate the equilibrium (play fair,cheat,0). However, it is reasonable to think that this difference between students must be reflected either in their disutility of effort or utility of grades. Other alternative is to consider that students have different seating positions in classroom, and one of them is in a position that makes cheating easier. Once again, this may solve the coordination problem, but different positions in classroom may also indicate that the probabilities of being caught cheating are different as well, which would imply that students are not homogeneous.

The same coordination difficulties arise when we study the other possible equilibria. For example, when professor chooses $\theta^{*}>0$ but $p^{*}<p^{\min }$, we have (play fair,cheat, $\theta^{*}$ ) and (cheat,play fair, $\theta^{*}$ ) as equilibria, and the same reasoning made above applies. When his choice is $\theta^{*}>0$ and $p^{*}=p^{\min }$, we have the two previous equilibria plus the virtuous one. Once again there is a coordination problem and now it is even more severe, once the choice is among three different results. Notice that in this latter case, the multiplicity arises because the punishment level makes students be indifferent between playing fair and cheating. One possible focal point here is the existence of some cultural aspect which states that studying is more valued by society than cheating. Nevertheless, the difficulties aforementioned remain.

Finally, there are scenarios in which the severe professor is indifferent between $\theta^{*}=0$ and $\theta^{*}>0$. The interpretation of these results is quite the same as before. Furthermore, when this is the case, there is a possibility of a result with five Nash equilibria, namely when $p^{*}=p^{\min }$. The coordination problem is even more severe now, but we can think of a focal point involving some cultural aspect about the professor's behavior. Society may be consider high effort worthy, which would lead professor and students to choose the virtuous equilibrium.

\section{EXTENSIONS}

\subsection{The baseline model with incomplete information}

A natural extension of our baseline model is to consider that students do not observe the type of the professor, whether lenient or severe. In order to see how this feature affects the results obtained in the baseline case, let us assume that both students know-in fact, it is common knowledge- that the professor is lenient with probability $q \in(0,1)$ and severe with probability $1-q$. In addition, we restrict to the case in which condition (10) holds, since when it does not, the professor's expected level of effort is null, and thus the result is trivial.

The professor's expected level of effort is therefore $\mathbb{E}[\theta]=(1-q) \theta^{*}$, where $\theta^{*}>0$ because condition (10) is assumed to be satisfied. Associated to this effort, there is the expected probability of being caught cheating, namely $p^{E}=p\left((1-q) \theta^{*}\right)$. Given that the probability is an increasing function of $\theta$, it is straightforward to notice that $p^{E}<p^{*}$. The first conclusion we can draw is that uncertainty increases the chances of cheating, when compared to the case with $\theta^{*}>0$, because now students expect a lower probability of being caught. For example, if the severe professor is such that $p^{*}>p^{\min }$, then for high enough $q$ we can have $p^{E}<p^{\min }$. Thus, the severe professor is worse off, since now a higher level of effort is necessary to make students' best choice be playing fair. This implies that the virtuous equilibrium will be reached only when the severe professor has lower disutility of effort or higher utility from the fairness in classroom. 
From the lenient professor's point of view, uncertainty may bring fairness to the classroom: when students are sure about his type, they know that $p=0$ and then will cheat (in equilibrium, only one of them will, as we have seen); but with incomplete information, it is possible that the severe professor is such that $p^{*}>p^{\min }$ and $q$ is low enough, such that $p^{E}>p^{\min }$, which make students play fair. Therefore, the presence of uncertainty may change students' behaviors and even the game's equilibria. In particular, while it may be harder for the severe professor to reach a virtuous outcome, it may facilitate the occurrence of such equilibrium when the professor is lenient.

\subsection{Professor punishes both students}

One can argue that the professor faces a further difficulty in trying to catch dishonest students: once he finds out that there is cheating in classroom, the task of identifying who the offender is may be hard. Let us investigate how our results change when at least one of the students is caught cheating and both are punished. Initially, observe that the expected grades when both cheat and both plays fair do not change. Instead, when student $A$ plays fair and student $B$ cheats, their grades now are $N_{A}=N_{B}=N_{A}\left(e_{A}^{*}\right)(1-p)$. Further, when students switch their roles, we have $N_{A}=N_{B}=N_{B}\left(e_{B}^{*}\right)(1-p)$.

It is straightforward to see that, assuming the above modification, there is no change in the results of the baseline model when the professor is lenient or is severe and condition (10) does not hold. Thus, we must analyze the case in which the professor's choice is $\theta^{*}>0$. In order to do so, first suppose that $B$ plays fair, and notice that the necessary and sufficient condition for $A$ to play fair is the same of the baseline case. When $B$ cheats, playing fair continues to be the best response of student $A$, because $U_{A}\left(N_{A}\left(e_{A}^{*}\right)(1-p), e_{A}^{*}\right)>0=U_{A}(0,0)$. The conclusion is that there is no change in the equilibria, which implies that our original assumption may be hold without loss of generality.

However, the results of the baseline model may change when we add a disutility from being unfairly punished. Assume that student $i$ has an extra desutility $c>0$ when he is punished by the professor and he did not cheat. In this case, the payoff of student $A$ when he plays fair and his classmate cheats is $U_{A}\left(N_{A}\left(e_{A}^{*}\right)\left(1-p^{*}\right), e_{A}^{*}\right)-p^{*} c$. Now, the best response of student $A$ if $B$ cheats depends on the value of $c$ as well. For example, for $c>c_{\min }$, where $c_{\min }=U_{A}\left(N_{A}\left(e_{A}^{*}\right)(1-p), e_{A}^{*}\right) / p^{*}$, student $A$ chooses to cheat. Thus, assuming that students are homogenous, we would have an equilibrium in which the students' best choices are (cheat, cheat).

\subsection{Imperfect cheating technology}

Suppose now that when one student copies his classmate's exam he is not able to achieve the same grade that the classmate does. We can justify such assumption by arguing that, due to the illegal character of cheating activities, in most of the cases students have difficulty to copy the whole exam, and thus his grade must only partially reflect the grade of the other student. We can model this by including a "discount factor" $\delta \in(0,1)$ in the cheater's grade. For example, when $A$ cheats and $B$ plays fair, the grade of student $A$ is $N_{A}=N_{B}\left(e_{B}^{*}\right)(1-p) \delta$. Observe that $\delta$ can be seen as a measure of the "cheating technology", such that, when the technology is perfect, $\delta=1$, we have the baseline case. Throughout this section we assume that $\delta$ is the same for both students. The case in which $\delta_{A} \neq \delta_{B}$ is quite similar and does not change the main result below.

The first aspect to be noted in this scenario is that student's the best response when his classmate cheats continues to be paying fair. However, now when student $B$ cheats and $\theta^{*}>0, A$ plays fair if and only if

$$
U_{A}\left(N_{A}\left(e_{A}^{*}\right)\left(1-p^{*}\right) \delta, 0\right) \leq U_{A}\left(N_{A}\left(e_{A}^{*}\right), e_{A}^{*}\right) .
$$

This implies that $p_{\delta}^{\min }<p^{\min }$, where $p_{\delta}^{\min }$ is the minimum probability that makes student $A$ plays fair when the cheating technology is imperfect. The conclusion is that now there is a stronger incentive to play fair. Once cheating is not effective as it is in the baseline model, this result is somehow expected. 
The interesting novel result appear when one considers the case in which $\theta^{*}=0$. Recall that in the baseline model, student $A$ chooses to cheat if student $B$ chooses to play fair, because $U_{A}\left(N_{B}\left(e_{B}^{*}\right), 0\right)>$ $U_{A}\left(N_{A}\left(e_{A}^{*}\right), e_{A}^{*}\right)$. With imperfect cheating technology, this best response may change. Observe that the student $A$ chooses to cheat if the student $B$ chooses to play fair if and only if

$$
U_{A}\left(N_{A}\left(e_{A}^{*}\right), e_{A}^{*}\right) \geq U_{A}\left(N_{B}\left(e_{B}^{*}\right) \delta, 0\right)=U_{A}\left(N_{A}\left(e_{A}^{*}\right) \delta, 0\right),
$$

where we continue to assume that students are homogeneous. Thus, for low enough $\delta$, (12) holds with strictly inequality, which means that equilibria when $\theta^{*}=0$ may change. This result is summarized in the next proposition.

Proposition 10. Suppose that the cheating technology is imperfect, that is, $\delta \in(0,1)$, such that the cheater's grade is strictly lower than the one of his classmate, who had the exam copied. Then, there exists $\tilde{\delta} \in(0,1)$ that makes playing fair be a dominant strategy for both students. Moreover, in this case, the virtuous equilibrium is the unique Nash equilibrium for each type of professor.

\subsection{Direct impact of cheating on "victim's" welfare}

Suppose that the student whose exam is copied has a further disutility from the fact of being victim of his classmate. We can justify this by assuming that he considers unfair that someone else benefits from his own effort. The simplest way to model such situation is to subtract from the students' utility function a disutility $d>0$, such that, for example, when student $A$ plays fair and student $B$ cheats, the welfare of the former becomes $U_{A}\left(N_{A}\left(e_{A}^{*}\right), e_{A}^{*}\right)-d$ while there is no change for the latter. One can note that this modification is quite similar to one in which there is a disutility from being unfairly punished. In fact, the results of both extensions are identical: if $d$ is low enough, there is no change in equilibria; however, if $p^{*}<p^{\min }$ and $d$ is large enough, then equilibrium involving (cheat, cheat) emerges.

Let us now consider the case in which the student who decides to play fair can avoid that his classmate succeeds in the attempt of copying the exam. A possible way to avoid the successful cheating is to cover the exam with his body, such that the classmate would be not able to see it. Other alternative is to write the answers with a small handwriting, which would make it difficult the task of copying. In any case, the student who is trying to avoid cheating exerts an additional effort, and this can divert his attention from the exam itself to the protection task. We model the effort's effect on his utility by assuming that his grade decreases whenever he engages in avoiding cheating, such that now $N_{A}=$ $N_{A}\left(e_{A}^{*}\right) \gamma$, where $\gamma \in(0,1)$ is a discount factor. Observe that $\gamma$ can be understood as a measure of how efficient the protection effort is. We also assume that once an effort is exerted, the cheating behavior does not succeed, that is $N_{B}=0$. Therefore the studying student faces the following trade-off: he may exert an effort in order to guarantee that his exam will not be copied, and thus he will not have the disutility $d$; or he may do nothing, which implies he has no cost in terms of grade, but his utility will be affected by $d$.

As a simplifying assumption, let $\gamma$ be the same for both students. We also assume that $d$ is not large enough, such that cheating is never a best response when the other student also cheats. Now, each student has a set of strategies with three elements, namely playing fair; playing fair, avoiding the copy; and cheating. Let us start by studying the best choices of student $A$ when the professor is lenient or severe and condition (10) does not hold, that is, when $\theta^{*}=0$. When $B$ plays fair and avoids the copy, $A$ prefers to play fair without avoiding the copy, because $U_{A}\left(N_{A}\left(e_{A}^{*}\right), e_{A}^{*}\right)>U_{A}\left(N_{A}\left(e_{A}^{*}\right) \gamma, e_{A}^{*}\right)>U_{A}(0,0)$. When $B$ plays fair and does not avoid the copy, the best choice of student $A$ is to cheat, since that $U_{A}\left(N_{B}\left(e_{B}^{*}\right), 0\right)>U_{A}\left(N_{A}\left(e_{A}^{*}\right), e_{A}^{*}\right)>U_{A}\left(N_{A}\left(e_{A}^{*}\right) \gamma, e_{A}^{*}\right)$, where once again we consider that students are identical. 
The most interesting case appears when student $B$ cheats. Now $A$ chooses to play fair and avoid to have the exam copied if and only if

$$
U_{A}\left(N_{A}\left(e_{A}^{*}\right) \gamma, e_{A}^{*}\right) \geq U_{A}\left(N_{A}\left(e_{A}^{*}\right), e_{A}^{*}\right)-d,
$$

which can be rewritten as

$$
d \geq U_{A}\left(N_{A}\left(e_{A}^{*}\right), e_{A}^{*}\right)-U_{A}\left(N_{A}\left(e_{A}^{*}\right) \gamma, e_{A}^{*}\right) .
$$

The conclusion is that student $A$ avoids the copy if and only if the disutility of having the exam copied is relatively higher than the utility loss caused by the discount factor $\gamma$. Furthermore, the higher $\gamma$, the lower the right-hand side of (13), and thus the lower is the mininum value of $d$ required to choose to avoid the copy. Other important result is that when (13) holds with strict inequality, there is no Nash equilibrium in pure strategies. In fact, there is no equilibrium which involves the avoiding behavior. Therefore, when (13) does not hold —or holds with equality—equilibria of the case $\theta^{*}=0$ are (cheat,play fair and does not avoid,0) and (play fair and does not avoid,cheat,0), which are the same of the baseline model.

When $\theta^{*}>0$, the best response of student $A$ for when student $B$ chooses to play fair and avoids the copy is the same of the previous case, since that the payoffs does not change. When $B$ cheats, once again the payoffs of $A$ does not change, such that his best response depends on whether the condition (13) holds, like in the case in which $\theta^{*}=0$. Finally, when student $B$ plays fair and does not avoid the copy, the choice of student $A$ is to play fair if and only if $U_{A}\left(N_{A}\left(e_{A}^{*}\right), e_{A}^{*}\right) \geq U_{A}\left(N_{B}\left(e_{B}^{*}\right)\left(1-p^{*}\right), 0\right)$, like in the baseline case. This allows us to sum up the conclusions of this section: whenever $p^{*}<p^{\min }$ and (13) holds with strict inequality, there is no Nash equilibrium in pure strategies; if $p^{*}<p^{\min }$ and (13) does not hold—or holds with equality—, we have the same equilibria of the baseline case; if $p^{*}>p^{\min }$ we also have the same equilibrium of the baseline case. Therefore, the possibility of avoiding the copy depends on the magnitudes of $d$ and $\gamma$, and when it appears to be optimal to avoid, there is no Nash equilibrium.

\subsection{Harder punishment}

Consider the case when there exists a further punishment for the dishonest student. For example, assume that the institution (school, college or university) has a code of ethical conduct (academic honor code) that establishes punishments such as failing grade in the course, suspension or expulsion. Let $F>0$ be the constant disutility of this punishment, such that now the student's expected utility when he chooses to cheat is $U_{i}\left(N_{j}\left(e_{j}^{*}\right)\left(1-p^{*}\right), 0\right)-p^{*} F$. Assume also that this further punishment does not affect the professor's utility - there is no cost to implement it, for example.

The best choice analysis here is quite similar to that of section 2.1.1. In fact, when $\theta^{*}=0$, there is no difference in the equilibria of the above matrices: given the professor's choice, student $A$ plays fair and student $B$ cheats and; student $A$ cheats and student $B$ plays fair. However, notice that when $\theta^{*}>0$ students face a further incentive to play fair, namely the punishment $F$. This new feature does not change the way they make their best choices. For example, student $A$ chooses to play fair if and only if

$$
U_{A}\left(N_{A}\left(e_{A}^{*}\right), e_{A}^{*}\right) \geq U_{A}\left(N_{B}\left(e_{B}^{*}\right)\left(1-p^{*}\right), 0\right)-p^{*} F .
$$

Therefore, given $p$, the equilibria of the second payoff matrix are still the same, but now the value of $p^{\min }$ is different, as the next result states.

Proposition 11. Suppose that if the student is caught cheating, his grade is set to zero and he is punished by losing $F>0$ of utility. Then there exists a probability of being caught cheating $\hat{p}^{\mathrm{min}} \in(0,1)$ such that

$$
U_{i}\left(N_{i}\left(e_{i}^{*}\right), e_{i}^{*}\right)=U_{i}\left(N_{j}\left(e_{j}^{*}\right)\left(1-\hat{p}^{\min }\right), 0\right)-\hat{p}^{\min } F,
$$


for $i, j=A, B$ and $i \neq j$. Moreover, $d \hat{p}^{\min } / d F<0$, and in particular, $\hat{p}^{\min }<p^{\min }$, where $p^{\min }$ is defined in the proposition 8.

In fact, this further punishment may be large enough to make both students choose to play fair regardless the probability of being caught cheating, as the next corollary shows.

Corollary 1. For any given probability of catching students cheating $p \in(0,1]$, there exists a punishment level $F^{\min }>0$ such that if $F>F^{\min }$, then playing fair is a strictly dominant strategy for both students.

The above results are similar to those of seminal study of Becker (1968), in particular, if the cost of committing an offense increases, ceteris paribus, potential offenders will be less prone to do it. Further, the punishment may be large enough to make all of them choose not to commit the offense. This may make us conclude that having a fair class, without cheating, is just a matter of choosing the correct level of punishment $F$. However, there is an underlying assumption in our framework that may be contested, namely there is no cost for the professor to implement this further punishment. As the empirical literature reports (e.g. McCabe et al., 2001), a considerable number of professors claim to treat in-class cheating lightly because of the bureaucratic costs associated to all the steps of a process of punishment.

Thus, in order to make the above analysis more realistic and interesting, let us consider that, before the exam starts - in the beginning of the course, for example - , the two types of professor (lenient and severe) can choose to send a signal about their behavior to the students. The professor who decides to send the signal says that the student caught cheating will have the further punishment $F>0$, like those cited above. However, now there is a cost to implement the punishment $\xi>0$, which creates a trade-off for the professor. In addition let us assume that the professor has a disutility $\psi>0$ whenever at least one student cheats.

It is fundamental in our model that when the professors announce the punishment in the beginning of the course, they are able to commit to carrying out their promises. It may be hard to envision how such commitments would be possible in a one-shot course, so students might be suspicious of those threats. However, professors might have an incentive to carry through on their promises if they teach this course every year and if they care about their reputation for telling the truth. One possible manner of making such promise credible is to state it formally in writing in the course's syllabus. The one-shot course with commitment can be viewed as a kind of analytical shorthand for a repeated game in which professors value their reputations.

Other important assumption we make is that it is common knowledge that professor is lenient with probability $q$ and severe with probability $1-q$. We also assume that the severe professor always sends the signal $F>0$, that is, he always announces that there will be a harder punishment for cheaters. We can justify this by arguing that due to his characteristics, in particular his liking by fairness in classroom, his cost to implement the punishment is very low, or even zero. We also saw in section 3.1 that the severe professor is worse off when there is uncertainty, such that he always has incentives to distinguish himself from the lenient one. Therefore, our focus is to study under which circumstances the lenient professor chooses pay the cost to mimic the behavior of the severe.

Besides the prior $q$, students share a belief that the lenient professor chooses to send the signal $F>0$ with probability $\mu$, that is, $\operatorname{Prob}(F>0 \mid$ lenient $)=\mu$. The timing of the game is the following: nature assigns probabilities for both types of professors; the lenient one chooses whether to send the signal $F>0$; students observe the signal and so update their beliefs; then a static game identical to one of our baseline model is played. Notice that if the lenient professor chooses not to send the signal, then students knows for sure his type and the Nash equilibrium is (play fair,cheat,0) and (cheat,play fair,0).

When the lenient professor chooses $F>0$, after observing the signal, students believe that the professor is indeed the lenient with probability $\operatorname{Prob}($ lenient $\mid F>0)=\mu q /[\mu q+(1-q)]$. By doing the 
same reasoning, they also believe that $\operatorname{Prob}($ severe $\mid F>0)=(1-q) /[\mu q+(1-q)]$, where we use the Bayes rule in both cases. This set of beliefs allows to build the expected probability of being cheating: given that $\mathbb{E}[\theta]=\theta^{*}(1-q) /[\mu q+(1-q)]$, we have

$$
\hat{p}^{E}=p\left(\frac{\theta^{*}(1-q)}{(1-q)+q \mu}\right)<p^{*}=p\left(\theta^{*}\right),
$$

and the inequality holds because $p(\cdot)$ is a increasing function. Observe that we can compare this result to one of the case without signaling (section 3.1): $\hat{p}^{E}>p^{E}$, because $(1-q) /[\mu q+(1-q)]>1-q$. This is other piece of evidence that the severe professor has incentive to send the signal whenever his cost is low enough.

We must now analyze students' best responses. First, because lazy students are ruled out, when student $B$ cheats, student $A$ plays fair, since that $U_{A}(0,0)-\hat{p}^{E} F<U_{A}\left(N_{A}\left(e_{A}^{*}\right), e_{A}^{*}\right)$. Second, when student $B$ plays fair and $F>F^{\min }\left(\hat{p}^{E}\right)$, where $F^{\min }\left(\hat{p}^{E}\right)$ is defined as in corollary 1, then playing fair is the best response for student $A$ as well. If $F<F^{\min }\left(\hat{p}^{E}\right)$ and student $B$ plays fair, student $A$ plays fair if and only if condition (14), with $\hat{p}^{E}$ replacing $p^{*}$, holds, which can be seen as $\hat{p}^{E} \geq \hat{p}^{\min }$. We have therefore two cases to analyze.

The first one is when the severe professor is such that $p^{*} \leq \hat{p}^{\min }$. This implies that $\hat{p}^{E}<\hat{p}^{\min }$, which means that the lenient professor does not have incentives to send the signal of harder punishment - and thus pay the cost $\xi$-, because the Nash equilibrium will be (play fair,cheat,0) and (cheat,play fair,0) by all means. Observe that this result is independent on the values of the parameters $q$ and $\mu$.

The second case is when $p^{*}>\hat{p}^{\min }$. Now, it is possible that $\hat{p}^{E} \geq \hat{p}^{\min }$ as long as $(1-q) /[(1-p)+q \mu]$ is close enough to 1 -for instance, when $q$ or $\mu$ are close to zero. If the values of $q$ and $\mu$ are such that $\hat{p}^{E}<\hat{p}^{\min }$, then we have the same result discussed above, namely the lenient professor chooses not to send the signal.

Finally, let us study the professor's choice. For, suppose that $\hat{p}^{E} \geq \hat{p}^{\mathrm{min}}$. With this expected probability of being caught cheating, each student chooses to play fair. Thus the lenient professor chooses to send the signal that a harder punishment will be implemented if and only if

$$
W^{L}\left(N_{A}\left(e_{A}^{*}\right), N_{B}\left(e_{B}^{*}\right), 0,0\right)-\xi \geq W^{L}\left(N_{A}\left(e_{A}^{*}\right), N_{A}\left(e_{A}^{*}\right), 0,0\right)-\psi .
$$

Observe that in the case of homogeneous students, with $N_{A}\left(e_{A}^{*}\right)=N_{B}\left(e_{B}^{*}\right)$, the condition above can be rewritten is a simpler way, namely $\xi \leq \psi$. We can sum up the conclusion about the lenient professor's behavior in the following way: he will send the signal and adopt a further punishment (pretending to be of the severe type) if and only if two conditions are satisfied, namely (i) $\hat{p}^{E} \geq p^{\min }$, which happens whenever $\mu$ and $q$ are low enough, or $p^{*}$ is high enough; and (ii) the cost of signaling is lower than the disutility from having someone cheating in classroom.

In Bayesian games terms, we can say that the existence of a pooling equilibria, in which the lenient professor mimics the behavior of the severe one by sending a signal that he will also adopt a harder punishment, depends on several factors: (i) before observing the signal, students must believe that the chance of the professor being lenient is low; (ii) students must believe that the probability that a lenient chooses to send a signal is low as well; (iii) there is a large difference between the severe and the lenient professor, reflected in the large probability of catching cheaters for the severe; and (iv) the magnitudes of the costs $\xi$ and $\psi$. Therefore, even when $\xi<\psi$ there is no guarantee that the lenient professor will send a signal. Finally, one can note, once again this kind of professor is better off when the uncertainty is high, reflected in low values of $\mu$ and $q$, for example.

\subsection{Heterogeneous students}

Let us now relax the assumption of symmetrical students. If students are no longer identical, they choose different levels of optimal effort. Without loss of generality, we assume that $e_{A}^{*}>e_{B}^{*}$. This can 
happen when they have similar utility functions, but different marginal disutility of effort, with the student $A$ 's disutility lower than the one of student $B$. We might also have assumed that either of other two items cited in proposition 3 differ among them, such that we would have the same result.

Given that the grade function is increasing in the student's effort, we have $N_{A}\left(e_{A}^{*}\right)>N_{B}\left(e_{B}^{*}\right)$. This inequality indicates that now the incentive for student $A$ to play fair is different than the one for student $B$. In fact, although student $B$ 's best choices are the same as they are in the symmetrical case, student $A$ 's decision depends on the magnitude of his disutility of effort as compared to the benefit from the increased grade. We must detail this difference below.

First observe that student $B$ behaves exactly in the same way he does in the baseline model: when professor chooses $\theta^{*}=0$, he plays fair if student $A$ cheats, and cheats if student $A$ plays fair, and; when professor chooses $\theta^{*}>0$, he plays fair if student $A$ cheats, and plays fair if student $A$ plays fair if and only if $p^{*} \geq p^{\min }$. Because of the difference between students, we now call this minimum probability $p_{B}^{\min }$. The next result shows that the existence of such an minimum probability is not guaranteed for student $A$.

Proposition 12. Suppose that $N_{A}\left(e_{A}^{*}\right)>N_{B}\left(e_{B}^{*}\right)$. Then there exists a probability of being caught cheating $\hat{p}_{A}^{\min } \in(0,1)$ for student $A$ such that

$$
U_{A}\left(N_{A}\left(e_{A}^{*}\right), e_{A}^{*}\right)=U_{A}\left(N_{B}\left(e_{B}^{*}\right)\left(1-\hat{p}_{A}^{\min }\right), 0\right),
$$

if and only if $U_{A}\left(N_{A}\left(e_{A}^{*}\right), e_{A}^{*}\right)<U_{A}\left(N_{B}\left(e_{B}^{*}\right), 0\right)$. Whenever $\hat{p}_{A}^{\min }$ exists, we have $\hat{p}_{A}^{\min }<\hat{p}_{B}^{\min }$.

Taking into account that $\partial U_{A} / \partial N_{A} \cdot N_{A}^{\prime}>0$ and $\partial U_{A} / \partial e_{A}<0$, the condition above is equivalent to saying that student $A$ 's marginal disutility of effort must be high enough to overcome the marginal benefit from the increase in his grade, when his level of effort is zero and his grade is $N_{B}\left(e_{B}^{*}\right)$. Whenever this condition fails, the utility from playing fair is higher than the one from cheating, regardless the professor's effort and the probability associated to this effort. In this case, when professor chooses $\theta^{*}>0$, playing fair is a dominant strategy for student $A$, since we know that he makes the same choice if the another student cheats (recall that $U_{A}\left(N_{A}\left(e_{A}^{*}\right), e_{A}^{*}\right)>0$ ).

The magnitude of the difference between their grades-and therefore between their levels of effort-is an important component of the above analysis. Let us show this by using extreme examples. Suppose initially that $N_{A}\left(e_{A}^{*}\right)$ is fixed and $N_{B}\left(e_{B}^{*}\right)=0$. One can readily see that $U_{A}\left(N_{A}\left(e_{A}^{*}\right), e_{A}^{*}\right)>$ $U_{A}(0,0)$, such that student $A^{\prime}$ 's best choice is to play fair, and this is completely independent of $p^{*}$. However, if $N_{B}\left(e_{B}^{*}\right)=N_{A}\left(e_{A}^{*}\right)$, we have seen that $U_{A}\left(N_{A}\left(e_{A}^{*}\right), e_{A}^{*}\right)<U_{A}\left(N_{A}\left(e_{A}^{*}\right), 0\right)$, which indicates a possibility of cheating, depending on the probability of being caught. The intuition underlying proposition 12 is that student $A$ 's grade may be much higher than the one of his classmate that the risk of cheating is not worth taking, even when there are very low chances of being punished.

Proposition 12 also states that when $\hat{p}_{A}^{\min }$ exists, it is lower than $\hat{p}_{B}^{\min }$. Once again, since $N_{A}\left(e_{A}^{*}\right)>$ $N_{B}\left(e_{B}^{*}\right)$, student $A$ 's gain by making a positive effort is higher than the one of the another student, as a result he is "more prone" to play fair than $B$. This is reflected in the minimum probability that induces the student to behave honestly. Thus, professor's best choice $\theta^{*}>0$ can now result in several possibilities: $p^{*}>p_{B}^{\min }>p_{A}^{\min }, p^{*}=p_{B}^{\min }>p_{A}^{\min }, p_{B}^{\min }>p^{*}>p_{A}^{\min }, p^{*}>p_{B}^{\min }=p_{A}^{\min }$ and $p_{B}^{\min }>p_{A}^{\min }>p^{*}$. As the FOC of professor's problem (2) shows, the chosen case will depend on his marginal utilities, mainly his disutility of effort. For example, if condition (2) holds when $-\partial W^{S} / \partial \theta$ is very large, then the concavity of $W$ implies that $\theta^{*}$ will be very low, such that we may have the fifth case.

The potential nonexistence of $p_{A}^{\min }$ creates a multiplicity of Nash equilibria in the cheating game with heterogeneous students, a number even larger than the one of the baseline model. Due to this, we constrain our main analysis only for the case in which $p_{A}^{\min }$ exists. When $U_{A}\left(N_{A}\left(e_{A}^{*}\right), e_{A}^{*}\right) \geq U_{A}\left(N_{B}\left(e_{B}^{*}\right), 0\right)$, student $A$ has a weakly dominant strategy, namely playing fair, such that it suffices to study the best choices of the other two players, and the results are quite similar to those of proposition 9. 
Proposition 13. Suppose that $e_{A}^{*}>e_{B}^{*}$. Then the game played by heterogeneous students $A$ and $B$ and the professor has a virtuous equilibrium if and only if $p^{*} \geq p_{B}^{\min }$, the professor is severe and condition (10) holds. Furthermore, if the above inequality is strict and condition (10) holds with strict inequality, then the equilibrium is unique.

The intuition of the above result is quite similar to one of the proposition 9, except by the difference between the minimum probabilities of being caught cheating necessary to make students $A$ and $B$ to play fair. Once again, a virtuous equilibrium requires that the professor exert a level of effort high enough to the probability associated be higher than that minimum level. As the higher the grade the lower the $p^{\mathrm{min}}$, a class composed by high effort students-because of their low disutility of effort, for example-makes the professor's task of maintaining fairness easier.

A possibility that is not exploited in this paper is the presence of more than two studentsidentical or not-in the classroom. This modification would make each student has more potential "victims", but at the same time there would be more potential "offenders" as well. Issues such as how to set students' seating position in order to minimize the chance of cheating would be possible to be studied when there are more players in the game. As we have seen in this section, if these students were heterogeneous, a plenty of possible outcomes would emerge and the differential between students' grades would have an important role.

\section{CONCLUDING REMARKS}

The novelty and main contribution of this paper is to highlight that cheating may be seen as a strategic choice, which involves cost-benefit analysis. In fact, our framework provides the microeconomic foundations of both student's choice of cheating or not and professor's choice of trying to catch dishonest students. By applying game theory's tools, we are able to better understand the determinants of academic dishonesty found by the literature, in a similar way the theoretical model of Becker (1968) has done with Economics of Crime. Our findings also provide further policy implications for cheating control in classroom. In particular, we emphasize the importance of professors being well-motivated (with low disutility of effort) and worried about fairness in classroom. Finally, we discuss the role of the students' uncertainty about the professor's type and how low effort professor can send signals to create incentives for honest behavior.

Our model is the first step towards a rigorous treatment of the strategic relationships underlying the students' choice of cheating or not. Therefore, there are several directions in which it can be extended. One that we believe to be promising is to explore even more the model with incomplete information. A student may be unsure about the other student's true grade—or his true effort level, his type ultimately - , which can be modeled by assuming that he has only a belief about it. Such an extension would allow the study of issues such as signaling, which in turn allows us to understand how professor can use the daily contact with students to prevent cheating. In this regard, repeated games also seem to be a good alternative to model the dynamics of the behaviors of both students and professor, and thus their daily contact. Other interesting extension involves to allow collaboration among students, both in take-home and in classroom tasks-with one deliberately trying to help other in the exam, for example-, which would contribute to the incipient literature started by Briggs et al. (2013). We believe that this approach may also provide alternative solutions to the coordination problems found in our model. 


\section{REFERENCES}

Baird, J. S., Jr. (1980). Current trends in college cheating. Psychology in the Schools, 17(4), 515-22.

Becker, G. S. (1968). Crime and punishment: An economic approach. Journal of Political Economy, 76(2), 169-217. Retrieved from http://www.jstor.org/stable/1830482

Bisping, T. O., Patron, H., \& Roskelley, K. (2008). Modeling academic dishonesty: The role of student perceptions and misconduct type. The Journal of Economic Education, 39(1), 4-21.

Briggs, K., Workman, J. P., \& York, A. S. (2013). Collaborating to cheat: A game theoretic exploration of academic dishonesty in teams. Academy of Management Learning \& Education, 12(1), 4-17.

Bunn, D. N., Caudill, S. B., \& Gropper, D. M. (1992). Crime in the classroom: An economic analysis of undergraduate student cheating behavior. The Journal of Economic Education, 23(3), 197-207.

García-Villegas, M., Franco-Pérez, N., \& Cortés-Arbeláez, A. (2015). Perspectives on academic integrity in Colombia and Latin America. In T. Bretag (Ed.), Handbook of academic integrity (pp. 161-180). Springer.

Gibson, K. (2003). Games students play: Incorporating the prisoner's dilemma in teaching business ethics. Journal of Business Ethics, 48(1), 53-64.

Macfarlane, B., Zhang, J., \& Pun, A. (2014). Academic integrity: A review of the literature. Studies in Higher Education, 39(2), 339-358.

McCabe, D. L., Trevino, L. K., \& Butterfield, K. D. (2001). Cheating in academic institutions: A decade of research. Ethics \& Behavior, 11(3), 219-232.

Michaels, J. W., \& Miethe, T. D. (1989). Applying theories of deviance to academic cheating. Social Science Quarterly, $70(4), 870$.

Stearns, S. A. (2001). The student-instructor relationship’s effect on academic integrity. Ethics \& Behavior, 11(3), 275-285.

The Guardian. (2016, January 2). Universities catch almost 50,000 student cheats. The Guardian.

Ward, D. A., \& Beck, W. L. (1990). Gender and dishonesty. The Journal of Social Psychology, 130(3), 333-339.

\section{APPENDIX. OMMITED PROOFS}

\section{A.1. Proposition 2}

Observe that

$$
\lim _{e_{i} \rightarrow+\infty} \frac{d U_{i}}{d e_{i}}=\lim _{e_{i} \rightarrow+\infty}\left(\frac{\partial U_{i}}{\partial N_{i}} N_{i}^{\prime}\right)+\lim _{e_{i} \rightarrow+\infty} \frac{\partial U_{i}}{\partial e_{i}} .
$$

Thus, by conditions (iii) and assumption $1, \lim _{e_{i} \rightarrow+\infty} d U_{i} / d e_{i}=\lim _{e_{i} \rightarrow+\infty} \partial U_{i} / \partial e_{i}=-\infty$. Recall that $U_{i}$ is $C^{2}$, such that $d U_{i} / d e_{i}$ is continuous. Moreover, by condition (i), $d U_{i} / d e_{i}(0,0)>0$. Thus, we can invoke the intermediate value theorem and conclude that there exists an interior point $e_{i}^{*}$ that satisfies (1).

We must now show that that $e_{i}^{*}$ is an unique global maximizer of the student's optimization problem. For, note that

$$
\frac{d^{2} U_{i}}{d e_{i}^{2}}=\frac{\partial^{2} U_{i}}{\partial N_{i}^{2}}\left(N_{i}^{\prime}\right)^{2}+\frac{\partial U_{i}}{\partial N_{i}} N_{i}^{\prime \prime}+2 \frac{\partial U_{i}^{2}}{\partial N_{i} \partial e_{i}} N_{i}^{\prime}+\frac{\partial^{2} U_{i}}{\partial e_{i}^{2}}<0,
$$

for all $e_{i}$, because of condition (ii), assumption 1 and $\partial U_{i} / \partial N_{i}>0$. This implies that $U_{i}$ is strictly concave in $e_{i}$. Therefore, the first order condition is sufficient to guarantee that $e_{i}^{*}$ is an unique global maximizer. 


\section{A.2. Proposition 3}

To prove the first claim of the proposition, suppose that student $A$ 's best choice $e_{A}^{*}$ satisfies (1). Suppose also that $\partial U_{A} / \partial N_{A}=\partial U_{B} / \partial N_{B}$ and $N_{A}^{\prime}=N_{B}^{\prime}$, but $\partial U_{A} / \partial e_{A}>\partial U_{B} / \partial e_{B}$. This implies that at $e_{B}=e_{A}^{*}$

$$
\frac{d U_{B}}{d e_{B}}=\frac{\partial U_{B}}{\partial N_{B}} N_{B}^{\prime}+\frac{\partial U_{B}}{\partial e_{B}}<0 .
$$

Thus, given that $d^{2} U_{i} / d e_{i}^{2}<0$, we must have $e_{B}^{*}<e_{A}^{*}$.

Second and third claims can be proved by using the same reasoning. For, suppose that $\partial U_{A} / \partial N_{A}>$ $\partial U_{B} / \partial N_{B}, N_{A}^{\prime}=N_{B}^{\prime}$, and $\partial U_{A} / \partial e_{A}=\partial U_{B} / \partial e_{B}$. Now observe that at $e_{B}=e_{A}^{*}$ we once again have (A-3), such that we can conclude that $e_{B}^{*}<e_{A}^{*}$. It is straightforward to see that the same inequality is found when we suppose that students have the same marginal utilities, but different returns of the effort on grades.

\section{A.3. Proposition 6}

Item (i) of assumption 4 implies $d W^{S} / d \theta$ is strictly decreasing in $\theta$. Moreover, by the definition of severe professor, $d W^{S} / d \theta>0$ when $\theta^{*}=0$. From item (ii) of assumption 4 we also have $\lim _{\theta \rightarrow+\infty} d W^{S} / d \theta=$ $-\infty<0$. Finally, given that $W$ is a $C^{2}$ function, its derivative is continuous. Thus, the intermediate value theorem applies and there exists an interior point $\theta^{*}$ that satisfies (2). This point is an unique global maximizer because $W$ is strictly concave in $\theta$.

\section{A.4. Proposition 7}

We employ the same reasoning of the proposition's 3 proof. We prove the proposition for the case when student $A$ cheats and student $B$ plays fair. Proofs for the remaining cases are straightforward and very similar to this one. Suppose that $\theta^{*}$ satisfies the severe professor's FOC (2). For the item (i), assume that all the derivatives of his utility function are fixed except his marginal disutility of the effort, which now is $\partial \hat{W}^{S} / \partial \theta<\partial W^{S} / \partial \theta$. This implies that at $\theta=\theta^{*}$

$$
p^{\prime}\left(\frac{\partial W^{S}}{\partial p}-\frac{\partial W^{S}}{\partial N_{A}} N_{B}\right)+\frac{\partial \hat{W}^{S}}{\partial \theta}<0 .
$$

Thus, given that $d^{2} W^{S} / d^{2} \theta<0$, we must have $\hat{\theta}<\theta^{*}$, where $\hat{\theta}$ solves

$$
p^{\prime}\left(\frac{\partial W^{S}}{\partial p}-\frac{\partial W^{S}}{\partial N_{A}} N_{B}\right)+\frac{\partial \hat{W}^{S}}{\partial \theta}=0 .
$$

For item (ii), assume that the only derivative that is not fixed is $\partial W^{S} / \partial N_{A}$, which now is $\frac{\partial \hat{W}^{S}}{\partial N_{A}}>$ $\frac{\partial W^{S}}{\partial N_{A}}$. One can see that at $\theta=\theta^{*}$ we once again have $d W^{S} / d \theta<0$, which implies $\hat{\theta}<\theta^{*}$. We can repeat the procedure for the other two items and find that $d W^{S} / d \theta>0$ when $\theta=\theta^{*}$. Therefore, in those cases $\hat{\theta}>\theta^{*}$.

\section{A.5. Proposition 8}

First, define a function $f:[0,1] \rightarrow \mathbb{R}$, given by $f(p):=U_{i}\left(N_{i}\left(e_{i}^{*}\right), e_{i}^{*}\right)-U_{i}\left(N_{j}\left(e_{j}^{*}\right)(1-p), 0\right)$. Then, observe that $f$ is continuous, because so is $U_{i}$, and

$$
f^{\prime}(p)=\frac{\partial U_{i}}{\partial N_{i}} p N_{i}>0,
$$


that is, $f(p)$ is strictly increasing for all $p \in[0,1]$.

Now we can compute

$$
\begin{aligned}
& f(0)=U_{i}\left(N_{i}\left(e_{i}^{*}\right), e_{i}^{*}\right)-U_{i}\left(N_{j}\left(e_{j}^{*}\right), 0\right)=U_{i}\left(N_{i}\left(e_{i}^{*}\right), e_{i}^{*}\right)-U_{i}\left(N_{i}\left(e_{i}^{*}\right), 0\right)<0 \\
& f(1)=U_{i}\left(N_{i}\left(e_{i}^{*}\right), e_{i}^{*}\right)-U_{i}((0,0))=U_{i}\left(N_{i}\left(e_{i}^{*}\right), e_{i}^{*}\right)>0,
\end{aligned}
$$

where we use the symmetry of the students and the fact that $U_{i}(0,0)=0$. Therefore, given that $p \in[0,1]$, the continuity of $f$ and $f^{\prime}(p)>0$, then there exists $p^{\min } \in(0,1)$ such that $f\left(p^{\min }\right)=0$, which is what had to be proven.

\section{A.6. Proposition 10}

Recall that, because our assumption that rules out "very lazy students", namely $\partial U_{i} / \partial e_{i}(0,0)>0$, when student $j$ chooses to cheat, student $i$ is better off by exerting some effort and thus chooses to play fair. If we show that there exists $\tilde{\delta} \in(0,1)$ such that $\partial U_{i} / \partial e_{i}\left(N_{j} \tilde{\delta}, 0\right)>0$ for $i=A, B$ and $j \neq i$, then student $i$ will exert a positive level of effort in every possible case, which implies that the strategy playing fair is dominant for both students and the profile (play fair,play fair) will be part of the equilibrium both when $\theta^{*}=0$ and $\theta^{*}>0$.

Let $N_{j}$ be a fixed grade and define $\partial U_{i} / \partial e_{i}(0,0)=\lambda>0$. Now, recall that $U(\cdot)$ is a $C^{2}$ function, such that $\partial U_{i} / \partial e_{i}$ is continuous in $\mathbb{R}^{2}$. Take a sequence $\left\{\delta_{k} N_{j}, 0\right\}_{k=1}^{\infty}$, where $\delta_{k}=\delta / k$ with $\delta \in(0,1)$ fixed and $k \in \mathbb{N}$, and observe that $\left(\delta_{k} N_{j}, 0\right) \rightarrow(0,0)$ as $k \rightarrow \infty$. By using the continuity property, we have that $\partial U_{i} / \partial e_{i}\left(N_{j} \tilde{\delta}, 0\right) \rightarrow \partial U_{i} / \partial e_{i}(0,0)=\lambda$ as $k \rightarrow \infty$, which means that there exists $\tilde{k}(\epsilon) \in \mathbb{N}$ such that if $k \geq \tilde{k}(\epsilon)$ then $\left|\partial U_{i} / \partial e_{i}\left(N_{j} \tilde{\delta_{k}}, 0\right)-\lambda\right|<\epsilon$. Define $\tilde{\delta}=\delta_{\tilde{k}(\epsilon)}=\delta / \tilde{k}(\epsilon)$, then we have $\partial U_{i} / \partial e_{i}\left(N_{j} \tilde{\delta}, 0\right)=\lambda$, because $\epsilon>0$ was arbitrary.

Finally, we have to prove that the virtuous equilibrium is unique for each type of professor. For the lenient one is trivial, once both students have playing fair as dominant strategy. Thus, the equilibrium is (play fair,play fair,0). The severe professor compares the following payoffs:

$$
W\left(N_{A}\left(e_{A}^{*}\right), N_{B}\left(e_{B}^{*}\right), 0,0\right)
$$

and

$$
W\left(N_{A}\left(e_{A}^{*}\right), N_{B}\left(e_{B}^{*}\right), \theta^{*}, p^{*}\right) .
$$

Given our assumptions and definition of severe professor, he chooses $\theta^{*}>0$ and the unique equilibrium is (play fair,play fair, $\theta^{*}$ ).

\section{A.7. Proposition 11}

The proof is similar to that of proposition 8 . First, define a function $g:[0,1] \rightarrow \mathbb{R}$, given by

$$
g(p)=U_{i}\left(N_{i}\left(e_{i}^{*}\right), e_{i}^{*}\right)-U_{i}\left(N_{j}\left(e_{j}^{*}\right)(1-p), 0\right)+p F
$$

and observe that $g(p)=f(p)+p F$, where $f$ is defined in proposition 8. In addition, $g(p)$ is strictly increasing because $g^{\prime}(p)=f^{\prime}(p)+F>0$ for all $p \in[0,1]$. By computing $g(0)=f(0)<0$ and $g(1)=$ $f(1)+F>0$, and recalling that $g(p)$ is continuous, because so is $f(p)$, we can once more invoke the intermediate value theorem to conclude that there exists a $\hat{p}^{\min } \in(0,1)$ such that $g\left(\hat{p}^{\min }\right)=0$.

We must now show that $\hat{p}^{\min }$ is decreasing in $F$. For the particular case $p=p^{\min }$, we have $g\left(p^{\min }\right)=$ $f\left(p^{\min }\right)+p^{\min } F=p^{\min } F>0$, where $p^{\min }$ is also defined in proposition 8. Given that $g^{\prime}(p)>0$ for all $p$, it must be the case that $\hat{p}^{\min }<p^{\min }$. For the general case, one can see that

$$
\frac{d \hat{p}^{\min }}{d F}=-\frac{\partial g / \partial F}{\partial g / \partial \hat{p}^{\min }}=-\frac{\hat{p}^{\min }}{F}<0,
$$

where we used the implicit function theorem. 


\section{A.8. Corollary 1}

Let $\bar{p} \in(0,1]$ be a given constant. Now we consider the function $h: \mathbb{R}^{*} \rightarrow \mathbb{R}$, given by

$$
h(F)=U_{i}\left(N_{i}\left(e_{i}^{*}\right), e_{i}^{*}\right)-U_{i}\left(N_{j}\left(e_{j}^{*}\right)(1-\bar{p}), 0\right)+\bar{p} F .
$$

Define

$$
F^{\min }=\frac{U_{i}\left(N_{j}\left(e_{j}^{*}\right)(1-\bar{p}), 0\right)-U_{i}\left(N_{i}\left(e_{i}^{*}\right), e_{i}^{*}\right)}{\bar{p}} .
$$

Observe that if $F>F^{\min }$, then $h(F)>0$, that is, playing fair is the best choice when the another student plays fair as well. Given that student $i$ also chooses to play when student $j$ cheats, the strategy is dominant when the above condition holds.

Now we have to consider three cases. First, if $\bar{p}>p^{\min }$, then the numerator of the above expression is negative, and so is $F^{\mathrm{min}}$. Therefore, in this case any punishment $F \geq 0$ guarantees that playing fair is a dominant strategic for both students. Second, if $\bar{p}=p^{\min }$, then $F^{\min }=0$, such that any positive punishment is sufficient for the result. Finally, if $\bar{p}<p^{\min }$, then $F^{\min }>0$ and we need that $F>F^{\min }$.

\section{A.9. Proposition 12}

First, suppose that $U_{A}\left(N_{A}\left(e_{A}^{*}\right), e_{A}^{*}\right)<U_{A}\left(N_{B}\left(e_{B}^{*}\right), 0\right)$ and consider again function

$$
f(p):=U_{i}\left(N_{i}\left(e_{i}^{*}\right), e_{i}^{*}\right)-U_{i}\left(N_{j}\left(e_{j}^{*}\right)(1-p), 0\right)
$$

with $i=A, j=B$ defined in the proof of proposition 8. Then, we have $f(0)<0$ and $f(1)>0$. Given that $f$ is $C^{2}$ and $f^{\prime}>0$ for all $p$, there exists a $\hat{p}_{A}^{\min } \in(0,1)$ such that $f\left(\hat{p}_{A}^{\min }\right)=0$.

Now, suppose that there exists a $\hat{p}_{A}^{\min } \in(0,1)$ such that $f\left(\hat{p}_{A}^{\min }\right)=0$. Then, for any $\epsilon>0$ small enough, $f\left(\hat{p}_{A}^{\min }+\epsilon\right)>0$ and $f\left(\hat{p}_{A}^{\min }-\epsilon\right)<0$, since that $f^{\prime}>0$ for all $p$. In particular, when $\epsilon=\hat{p}_{A}^{\min }$, we have $f\left(\hat{p}_{A}^{\min }-\epsilon\right)=f(0)<0$, which implies $U_{A}\left(N_{A}\left(e_{A}^{*}\right), e_{A}^{*}\right)<U_{A}\left(N_{B}\left(e_{B}^{*}\right), 0\right)$.

The final step of the proof is to demonstrate that $\hat{p}_{A}^{\min }<\hat{p}_{B}^{\min }$. This can be shown by calculating the following derivative:

$$
\frac{d p_{i}^{\min }}{d N_{i}\left(e_{i}^{*}\right)}=-\frac{\partial f / \partial N_{i}\left(e_{i}^{*}\right)}{\partial f / \partial p^{\min }}=-\frac{1}{N_{j}\left(e_{j}^{*}\right)(1-p)}<0,
$$

that is, the minimum probability of student $i$ decreases when his own grade increases, ceteris paribus. Therefore, if when the students are identical we have $\hat{p}_{A}^{\min }=\hat{p}_{B}^{\min }$, now the one with higher grade must have a minimum probability lower than his classmate. 